تسهيل جوانهزنى بذر هشت كونه زالزالى (Crataegus spp) بومى ايران با كاربرد

$$
\begin{aligned}
& \text { خراشدهى شيميايى و جينهسرمايى } \\
& \text { معصومه همتىفر '، على تهرانىفر "×."، بهرام عابدى "، حسن اكبرىبيشه F } \\
& \text { ' دانشجوى كارشناسى ارشد علوم باغبانى و فضاى سبز دانشخاه فردوسى مشهد }
\end{aligned}
$$

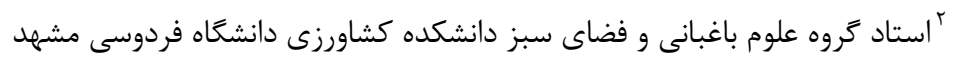

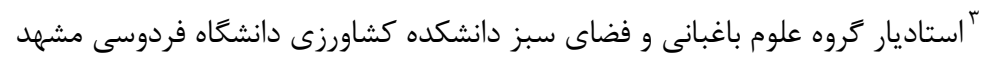

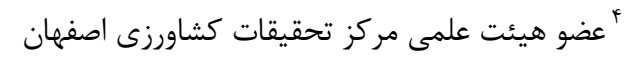

$$
\begin{aligned}
& \text { tehranifar@um.ac.ir : }
\end{aligned}
$$

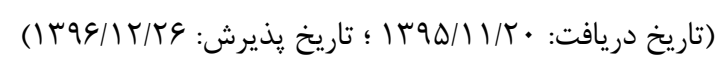

جكيده

با توجه به ارزش دارويى و زينتى زالزالك .Crataegus spp و نيز مشكلاتى كه در تكثير جنسى آن به دليل

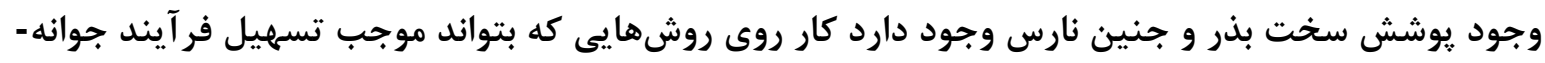

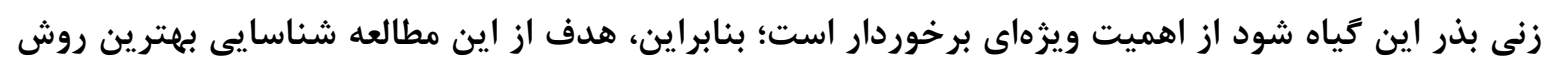

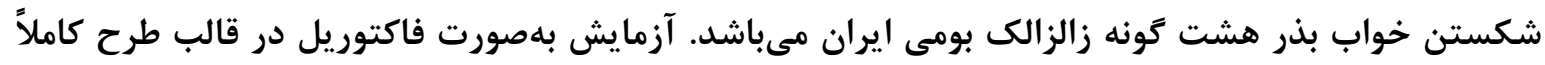

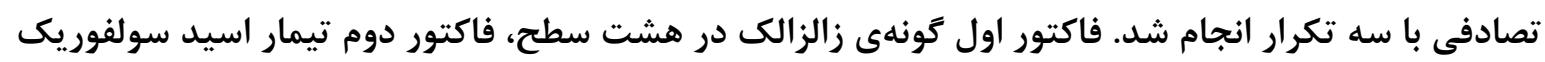
در سه سطح (نيم و يك ساعت غوطهورى در اسيد سولفوريك 919 بـ در مقابل عدم تيمار (شاهد)) و فاكتور

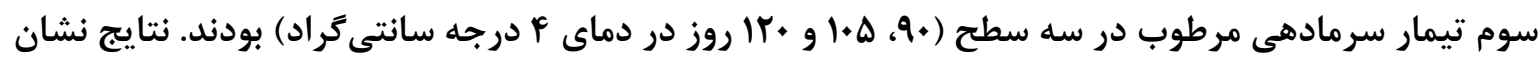

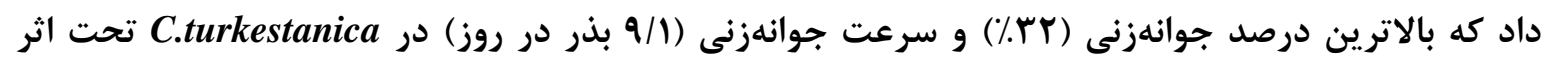

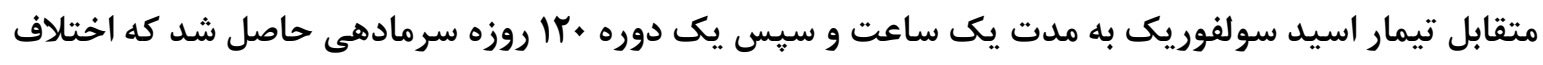

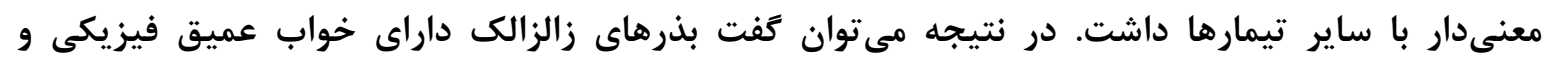

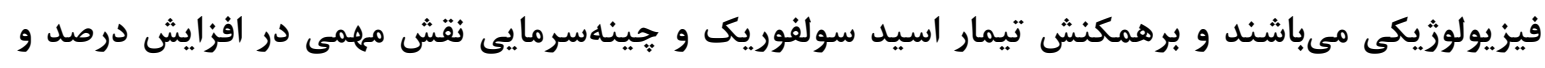
سرعت جوانهزنى بذر زالزالك ايفا نمود. وازههاى كليدى: اسيد سولفوريك، خواب بذر، درصد جوانهزنى، سرمادهى.

جنبdهاى نوآورى

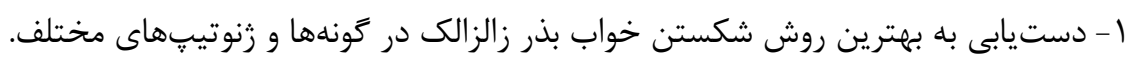

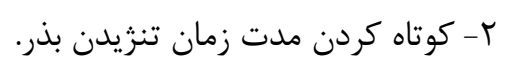

DOI: $10.29252 /$ yujs.4.2.13

CrossMark 
طولى جنين ضرورى بوده و انرزى فرآيندهاى متابوليكى

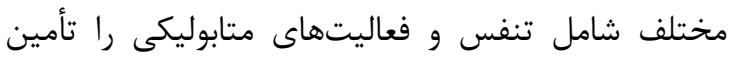

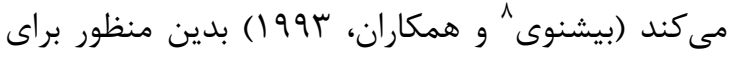
نفوذيذير كردن يوسته مىبايست از تيمارهاى سرمادهى،

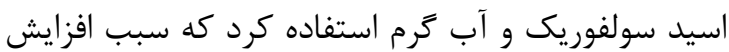
مقدار رطوبت بذر، مقدار اكسيزن و تسهيل در تبادل كازها و از طرفى حذف يا كاهش مواد بازدارنده جوانهزنى

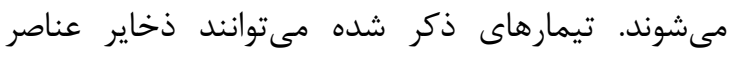

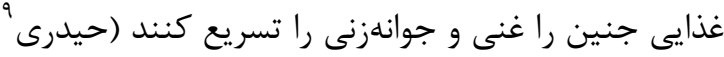

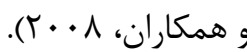

جهت نرم شدن يوسته سخت بذر علاوه بر سرماى مرطوب، مىبايست گرماى مرطوب جهت بيشرسى جنين نيز اعمال گردد كه اين سرمادهى و گرمادهى متناوب بلهواسطه اثرى كه در برطرف نمودن عوامل بازدارنده دارد سبب افزايش تعداد بذرهاى جوانهزده در واحد زمان و در در برد نهايت افزايش سرعت جوانهزنى مى كردد (ميرزاده واقفى و واند همكاران، • ( • (Y).

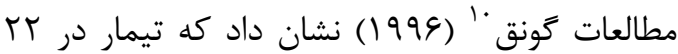

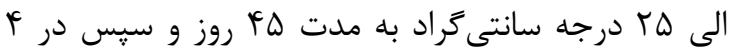
درجه سانتى بذر كونه Crataegus mollis نتيجه مثبتى داش داشت

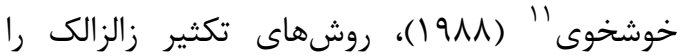

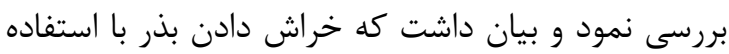

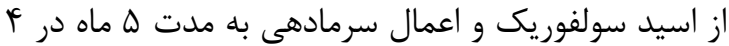
درجه سانتى

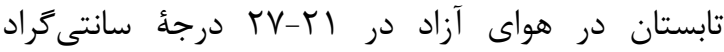

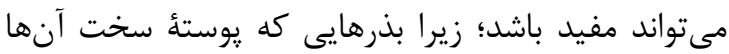
برطرف نمىشوند گاهى تا r سال طول مى كشد تا سبز

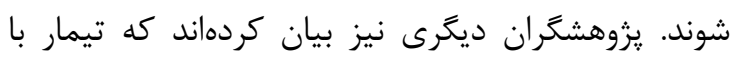
اسيد و به دنبال آن گرمادهى و سرمادهى، به شكستن خواب جنين و سرعت جوانهزنى كمك مى كند (بوزارسكا،

.$(Y \cdot 1)$

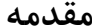
با صنعتى شدن جوامع و افزايش آلودگىهاى

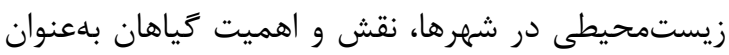

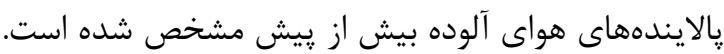

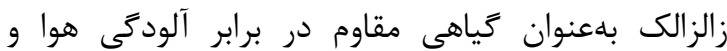
سازگار با انواع خاكها بهعنوان يك كياه زينتى به ميزان زيادى در يرجينسازى مورد استفاده قرار مى تيرد

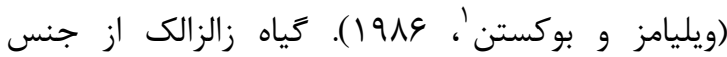
Crataegus تيره رز (Rosaceae)، راسته Rosales)، زيررده Cridae

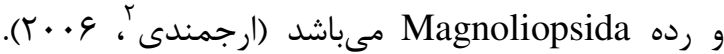

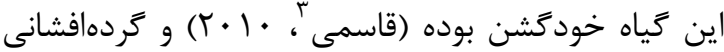
در آن بلصورت غيرتخصصى و توسط مخسها، سوسكها،

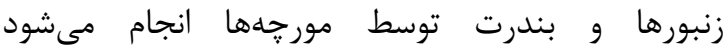

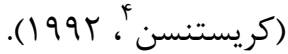
با وجود اهميت زالزالك در فضاى سبز متأسفانه تكثير

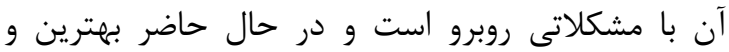

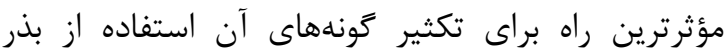

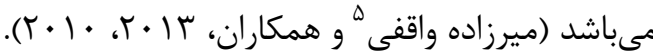
زالزالك از جمله كياهانى است كه جوانهزنى بذر آن

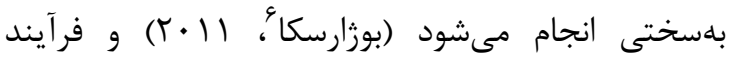

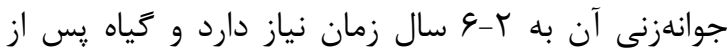

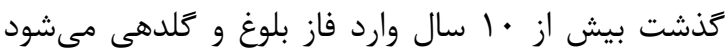
(كريستنسن، ب999). دو مكانيسم اصلى كه باعث ايجاد ركود در بذر اين جنس شدهاند عبارتاند از: انباشت بازدارندهاى رشد و توسعه يوششهاى بذر كه آبخيرى، قابليت نفوذ كازها و شسته شدن بازدارندهها را كنترل

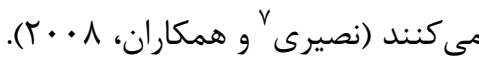

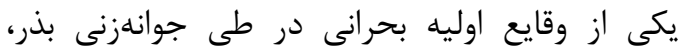
حركت ذخاير بذر (هيدروليز و انتقال) است كه براى رشد رداني

\footnotetext{
${ }^{1}$ Williams and Buxton

${ }^{2}$ Arjomandi

${ }^{3}$ Ghasemi

${ }^{4}$ Christensen

${ }^{5}$ Mirzadeh Vaghefi

${ }^{6}$ Bujarska

${ }^{7}$ Nasiri
} 
ابتدا ميوههاى رسيده در فصل پاييز به روش دستى

جمع آورى شده و در آزمايشعاه بذرها از كوشت ميوه جدا و با آب شسته شدند. براى تيمار خراشدهى شيميايى از اسيد سولفوريك غليظ (91.)، ساخت شركت مرك استفاده كرديد.

بدين ترتيب كه بذرها را به نسبت يك به جهار (بذر به اسيد) (نسبت حجمى) غوطهور كرده و يس از حذشت زمان موردنظر (نيم و يك ساعت)، براى از بين رفتن بقاياى اسيد و رفع موانع شيميايى از جمله بازدارندههاى

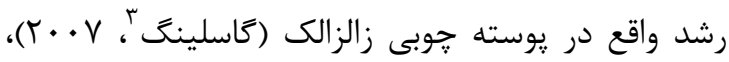

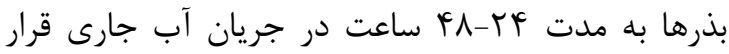
كرفتند. در اين يزوهش علاوه بر سرماى مرطوب (جهت نرم شدن يوسته سخت بذر)، گرماى مرطوب براى ييشرسى جنين نيز اعمال گرديد. براى انجام تيمار گرماى مرطوب: بعد از انجام تيمار اسيد، يك قسمت بذر با سه قسمت

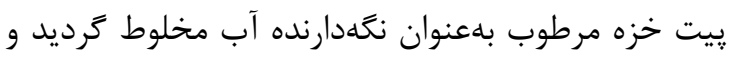
هر تيمار بلهصورت جداگانه در كيسههاى تورى يلاستيكى داخل كَلدانهاى بزرگ جعبهاى شكل حاوى ماسه و كوكوييت مرطوب به نسبت (:1:) داخل كلخانه گرم و مرطوب با دماى هr درجه سانتى گراد، به مدت • •9 روز

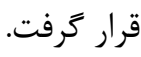

در تيمار سرمايى كيسههاى تورى حاوى بذر داخل كيسههاى يلاستيكى حاوى ماسه مرطوب قرار زرفت و در

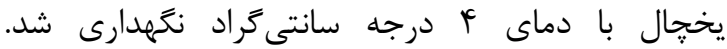
بذرهايى كه تيمار اسيد روى آنها اعمال نخرديد به مدت FF ساعت در جريان آب جارى بوده و سيس مراحل گرمادهى و سرمادهى مرطوب روى آنها اعمال گرديد. در

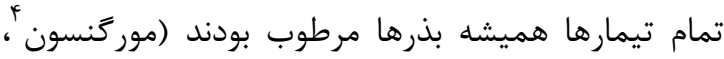

. (..$\cdot$

بعد از اعمال تيمارها، بذر در داخل كلدان و در هواى

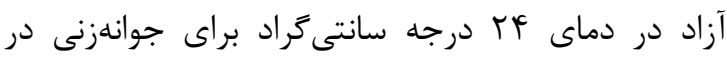
بستر كاشت خاك معمولى سترون شده كشت شدند.

\footnotetext{
${ }^{3}$ Gosling

${ }^{4}$ Morgenson
}

Fاربر و مورهد' (999) (19 براى جوانهزنى بذر گونههاى

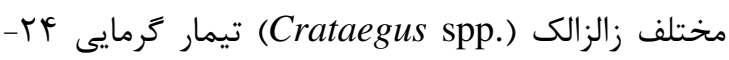

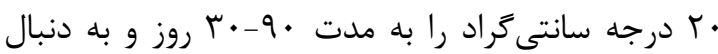

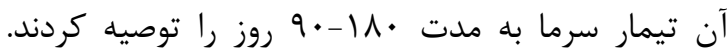

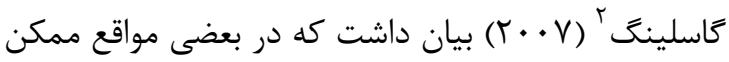

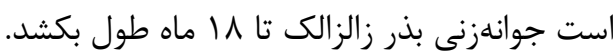
از آنجا كه براى شكستن خواب بذر اين گونهها بررسى بـى دقيق و جامعى نشده است، هدف از اين يزوهش بررسى نيازهاى جوانهزنى بذر و تعيين بهترين تيمارها براى شكست خواب بذر و جوانهزنى، كوتاه كردن مدت زمان تنزيدن بذور و در نتيجه حفظ ذخاير زنتيكى برخى كونههاى زالزالك كه در حال انقراض هستند، بوده است.

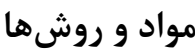

بلمنظور بررسى اثرات تيمارهاى مختلف بر شكستن

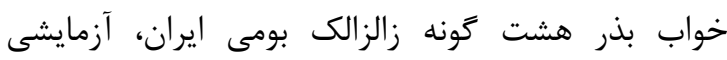
بهصورت فاكتوريل در قالب طرح كاملاً تصادفى با سه تكرار در كلخانه تحقيقاتى دانشكده كشاورزى دانشعاه

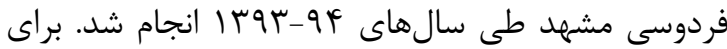
هر تيمار • له عدد بذر در نظر گرفته شد و برداشت ميوه زالزالك در ياييز سوسا انجام گرفت. تيمارهاى مورد مطالعه شامل: خراشدهى شيميايى با اسيد سولفوريك

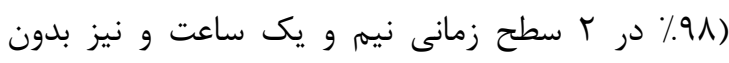

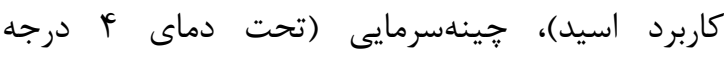
سانتى

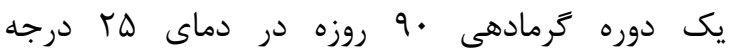
سانتى گراد جهت ييشرسى جنين براى تمامى گونهها نيز اعمال گرديد. هشت گونه زالزالك مورد استفاده شامل: C. microphylla $-C$. songarica $-C$. atrosanguina - C. pseudoheterophylla subsp. turkestanica - C. meyeri $-C$. ambigua $-C$. azarolus var. aronia - C. assadii از كونههاى جمع آورى شده از مناطق مختلف كشور (كلستان، بجنورد، اصفهان، قزوين و تبريز) مىباشند.

\footnotetext{
${ }^{1}$ Garber and Morhead

${ }^{2}$ Gosling
} 
همتىفر و همكاران: تسهيل جوانهزنى بذر هشت كونه زالزالك (Crataegus spp) بومى ايران...

Table 1. Specifications of habitats of wild hawthorn genotypes

$$
\text { جدول ا- مشخصات رويشعاه زنوتيبهاى وحشى زالزالى }
$$

\begin{tabular}{|c|c|c|c|c|}
\hline $\begin{array}{c}\text { شماره } \\
\text { Number }\end{array}$ & $\begin{array}{c}\text { نام علمى كياه } \\
\text { Scientific name of the plant }\end{array}$ & Native area & منطقه بومى & $\begin{array}{c}\text { موقعيت جغرافيايى } \\
\text { Geographic location }\end{array}$ \\
\hline 1 & $\begin{array}{l}\text { C. microphylla var. } \\
\text { microphylla }\end{array}$ & Golestan & كلمتان & $\begin{array}{c}\mathrm{H}: 501 \\
\mathrm{~N}: 37^{\circ} 02^{\prime} \text { 50.9" E:55 } 05^{\prime} 15.8^{\prime \prime}\end{array}$ \\
\hline 2 & $\begin{array}{l}\text { C. pseudoheterophylla } \\
\text { subsp. turkestanica }\end{array}$ & $\begin{array}{l}\text { North } \\
\text { Khorasan }\end{array}$ & خراسان شمالى & $\begin{array}{c}\mathrm{H}: 1125 \\
\mathrm{~N}: 37^{\circ} 30^{\prime} 55^{\prime \prime} \mathrm{E}: 57^{\circ} 09^{\prime} 02.1^{\prime \prime}\end{array}$ \\
\hline 3 & C. assadii & $\begin{array}{l}\text { North } \\
\text { Khorasan }\end{array}$ & خراسان شمالى & $\begin{array}{c}\mathrm{H}: 1125 \\
\mathrm{~N}: 37^{\circ} 30^{\prime} 55^{\prime \prime} \mathrm{E}: 57^{\circ} 09^{\prime} 02.1^{\prime \prime}\end{array}$ \\
\hline 4 & C. atrosanguinea & Esfahan & اصفهان & $\begin{array}{c}\mathrm{H}: 2285 \\
\mathrm{~N}: 31^{\circ} 31^{\prime} 14^{\prime \prime} \mathrm{E}: 51^{\circ} 22^{\prime} 20^{\prime \prime}\end{array}$ \\
\hline 5 & C. songarica & Qazvin & 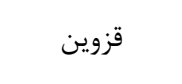 & $\begin{array}{c}\mathrm{H}: 1745 \\
\mathrm{~N}: 39^{\circ} 43^{\prime} 20^{\prime \prime} \mathrm{E}: 40^{\circ} 30^{\prime} 58.5^{\prime \prime}\end{array}$ \\
\hline 6 & C. ambigua & Qazvin & قزوين ق & $\begin{array}{c}\mathrm{H}: 1745 \\
\mathrm{~N}: 39^{\circ} 43^{\prime} 20^{\prime \prime} \mathrm{E}: 40^{\circ} 30^{\prime} 58.5^{\prime \prime}\end{array}$ \\
\hline 7 & C. meyeri & $\begin{array}{c}\text { East } \\
\text { Azarbaijan }\end{array}$ & آذربايجان & 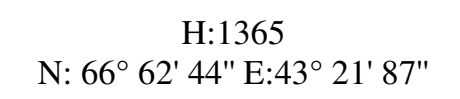 \\
\hline 8 & C. azarolus var. aronia & Kurdistan & 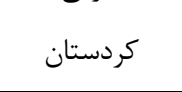 & $\begin{array}{c}\text { H: } 1950 \\
\text { N: } 36^{\circ} 13^{\prime} 42^{\prime \prime} \text { E: } 46^{\circ} 19^{\prime} 28^{\prime \prime}\end{array}$ \\
\hline
\end{tabular}

اسيد و سرمادهى در سطح احتمال يك درصد بر صفات

$$
\text { درصد و سرعت جوانهزنى بود. }
$$

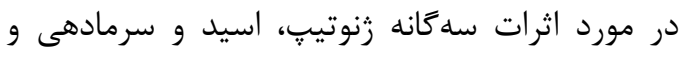

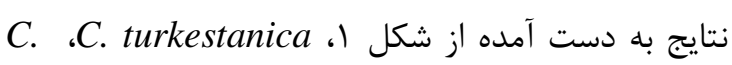

C. , C. aronia ،C. atrosanguina songarica

assadii

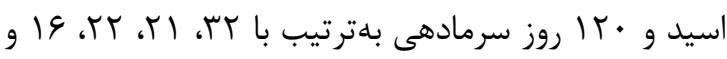

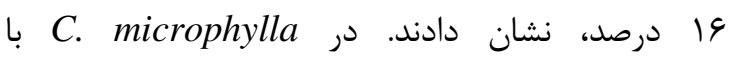
برهمكنش تيمار اسيد سولفوريك و سرمادهى، درصد بذر درد دران

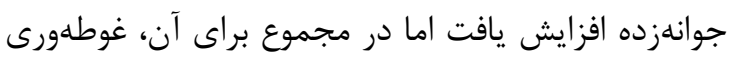

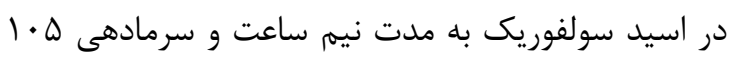

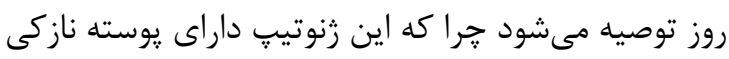

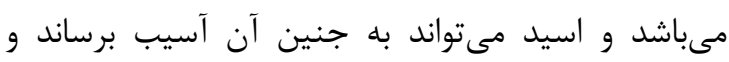

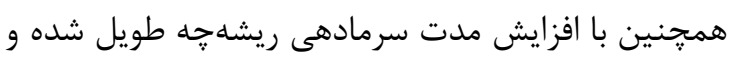

$$
\text { مناسب كشت مكانيكى نمىباشد. }
$$

$$
\begin{aligned}
& \text { با استفاده از روابط ا تا ז، سرعت جوانهزنى و درصد } \\
& \text { جوانهزنى محاسبه كرديد. } \\
& \text { رابطه (1): }
\end{aligned}
$$

.$(1994$

Di تعداد بذرهاى جوانهزده در روزهاى شمارش و ni

$$
\text { تعداد روز يس از شروع آزمايش است. }
$$

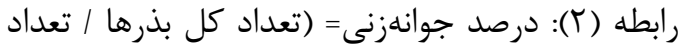

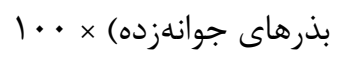

براى تجزيه و تحليل آمارى دادهها از نرمافزار

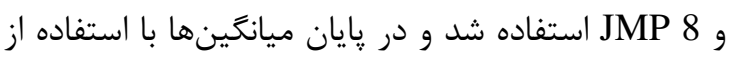

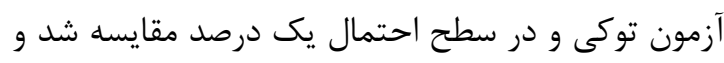

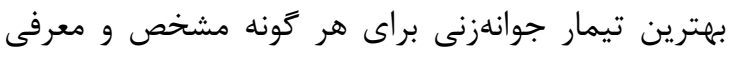
كرديد. - مبن.

\section{نتايج و بحث}

نتايج تجزيه واريانس (جدول بات ب) حاكى از معنادار

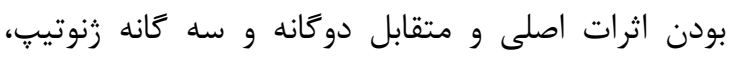

\footnotetext{
${ }^{1}$ Agrawal
} 


$$
\text { جدول r- تجزيه واريانس صفات جوانهزنى بذر زالزالك تحت تيمارهاى مختلف شكستن خواب بذر }
$$

Table 2. Analysis of variance of germination traits of hawthorn seeds under different treatments of seed dormancy breaking

\begin{tabular}{|c|c|c|c|c|}
\hline \multirow[b]{2}{*}{ Sources variation } & \multirow[b]{2}{*}{ منابع تغيير } & \multirow{2}{*}{$\begin{array}{c}\text { درجه آزادى } \\
\text { Degree of freedom }\end{array}$} & \multicolumn{2}{|c|}{$\begin{array}{c}\text { ميانگَين مربعات } \\
\text { Mean Squares } \\
\end{array}$} \\
\hline & & & $\begin{array}{c}\text { درصد جوانهزنى } \\
\text { Germination } \\
\text { percentage } \\
\end{array}$ & $\begin{array}{l}\text { سرعت جوانهزنى } \\
\text { Germination rate }\end{array}$ \\
\hline Sulfuric acid & اسيد سولفوريك & 2 & $1046.167^{\text {草 }}$ & $72.42681^{\text {***** }}$ \\
\hline Chilling & سرمادهى & 2 & $720.056^{\text {拳 }}$ & $56.15389^{\text {*** }}$ \\
\hline Genotype & رنوتي & 7 & $138.685^{\text {蔡 }}$ & $21.27439^{\text {絭 }}$ \\
\hline Acid $\times$ chilling & اسيد×سر مادهى & 4 & $257.389^{\text {单 }}$ & $22.16111^{\text {典 }}$ \\
\hline Acid $\times$ Genotype & اسيد×زنوتيب & 14 & $68.177^{\text {䖭 }}$ & $5.56882^{\text {**: }}$ \\
\hline $\begin{array}{l}\text { Chilling } \times \\
\text { Genotype }\end{array}$ & سرمادهى ×ثنوتي" & 14 & $100.479^{* * * *}$ & $7.96669^{* * *}$ \\
\hline $\begin{array}{l}\text { Acid } \times \text { Chilling } \times \\
\text { Genotype }\end{array}$ & اسيد×سرما×زنوتيت & 28 & $42.733^{\text {拳 }}$ & $4.29011^{\text {*.:. }}$ \\
\hline Error & خطا & 144 & 5.667 & 0.5813 \\
\hline $\begin{array}{l}\text { Coefficient of } \\
\text { variation }(\%)\end{array}$ & تغرصد ضريب & & 45.344 & 54.03 \\
\hline
\end{tabular}

assadii

اسيد و • Tا ا روز سرمادهى، C. meyeri،C. ambigua C. microphylla نيم ساعت اسيد و ه • إ روز سرمادهى داشتند. يزوهش هاى زير مؤيد اين موضوع است.

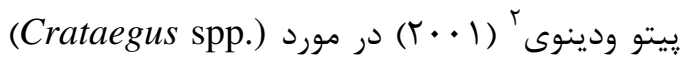
خواب بذر را از نوع درونى معرفى كردهاند و بيان داشتند

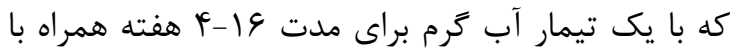
يك سرماى عس-r| هفتهاى برطرف مىشود و و خراشدهى قبل از ييش تيمار زرما به همراه سرما را مثمر ثمر ياد كردهاند.
C. ambigua و C. meyeri اسيد و ه • ا روز سرمادهى ڤياسخ بهترى نشان دادند اما با

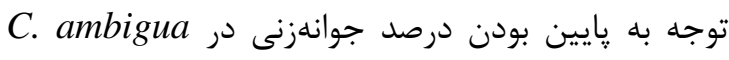
مىبايست مطالعه دقيقترى روى آن صورت گيرد. در برد مجموع برهمكنش تيمار اسيد سولفوريك و جينهسرمايى نقش مهمى در افزايش درصد و سرعت جوانهزنى بذر اكثر زنوتيڤها ايفا كردند و اين مسئله نشان مى مهد كه يكى از دلايل خواب در اين بذر از نوع فيزيكى و بهواسطه سختى يوسته آن است جرا كه خراشدهى بهوسيله اسيد و سرمادهى تا حد زيادى بر جوانهزنى مؤثر بوده و به جذب به بهرب رطوبت بيشتر و در نتيجه تنظيم هورمونى (جيبرليك اسيد و آبسيزيك اسيد) به نفع جوانهزنى بذر كمك كرده است (ميرزاده واقفى و نصيرى ؛ با • ب).

در مورد اثرات سهُانه زنوتيڤ، اسيد و سرمادهى و

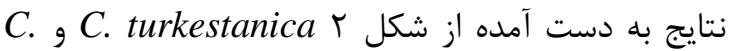
C. , C. aronia, C. atrosanguina, songarica

\footnotetext{
${ }^{1}$ Mirzadeh Vaghefi and Nasiri

\footnotetext{
${ }^{2}$ Peitto and Dinoi
} 
همتىفر و همكاران: تسهيل جوانهزنى بذر هشت تونه زالزالك (Crataegus Spp) بومى ايران...

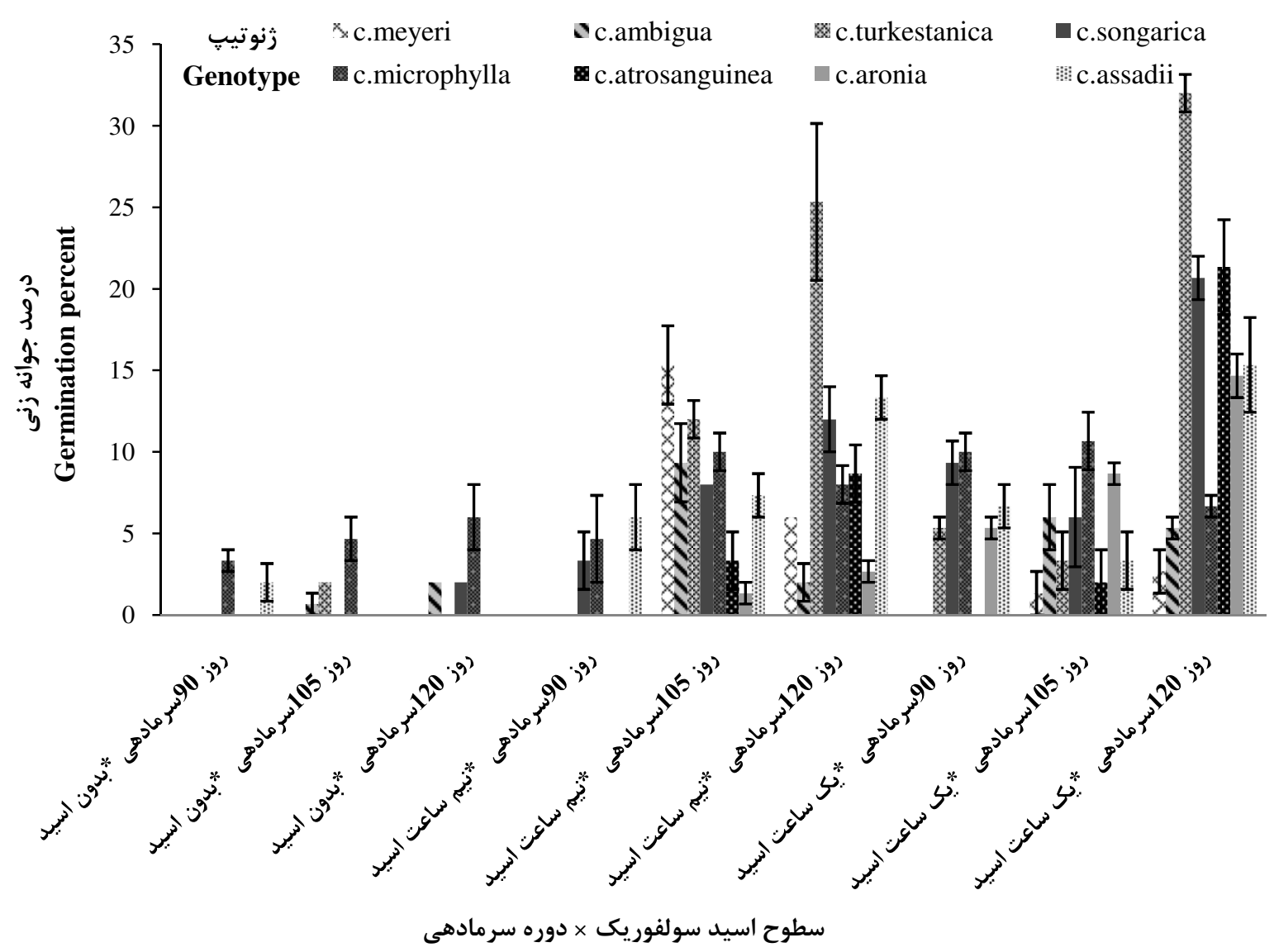

Sulfuric acid levels $\times$ chilling period

شكل ا- برهمكنش تيمارهاى اسيد سولفوريك، دوره سرمادهى و زُنوتيٍ براى درصد جوانهزنى. بارها نشاندهنده خطاى استاندارد ميانكَينها مىباشند (در r تكرار(

Figure 1. Effect of interactions of sulfuric acid, chilling period and genotype on germination percentage. The bars represent the standard error of the means (in 3 replications).

جوانهزنى زمانى مشاهده شد كه بذور بدون خراش بودند در حالى كه دورههاى سرما و گرما را طى كرده بودند. اسيد سولفوريك قادر است با كاهش استحكام يوسته

بذر و نقش بازدارندگى آن، سبب افزايش جوانهزنى و

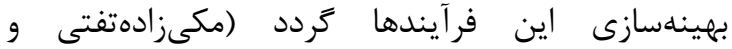

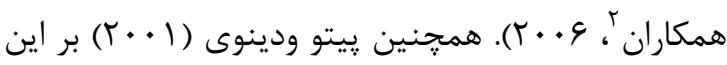
باورند كه گذشتن دو بهار در طبيعت با تيمار اسيد سولفوريك (از • ب دقيقه تا r ساعت براى C.monogyna

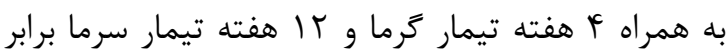
است. سرمادهى نيز علاوه بر تهيه محركهاى جوانهزنى و

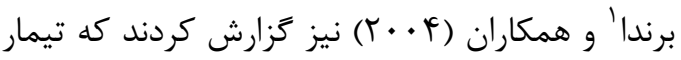

اسيد و به دنبال آن گرمادهى و سرمادهى به شكستن خواب جنين و سرعت جوانهزنى بذر زالزالى كمك مى كند. طبق تحقيقات ميرزاده واقفى و نصيرى (r| • ( ) نيز بالاترين درصد و سرعت جوانهزنى در زونه Crataegus assadii با دماى 1/ درجه سانتى گراد و به دنبال آن به مدت جههار و نيم ماه سرمادهى در أ درجه سانتى گراد روى بذرهاى خراش داده شده با سمباده حاصل گرديد و كمترين درصد

\footnotetext{
${ }^{1}$ Brenda
} 


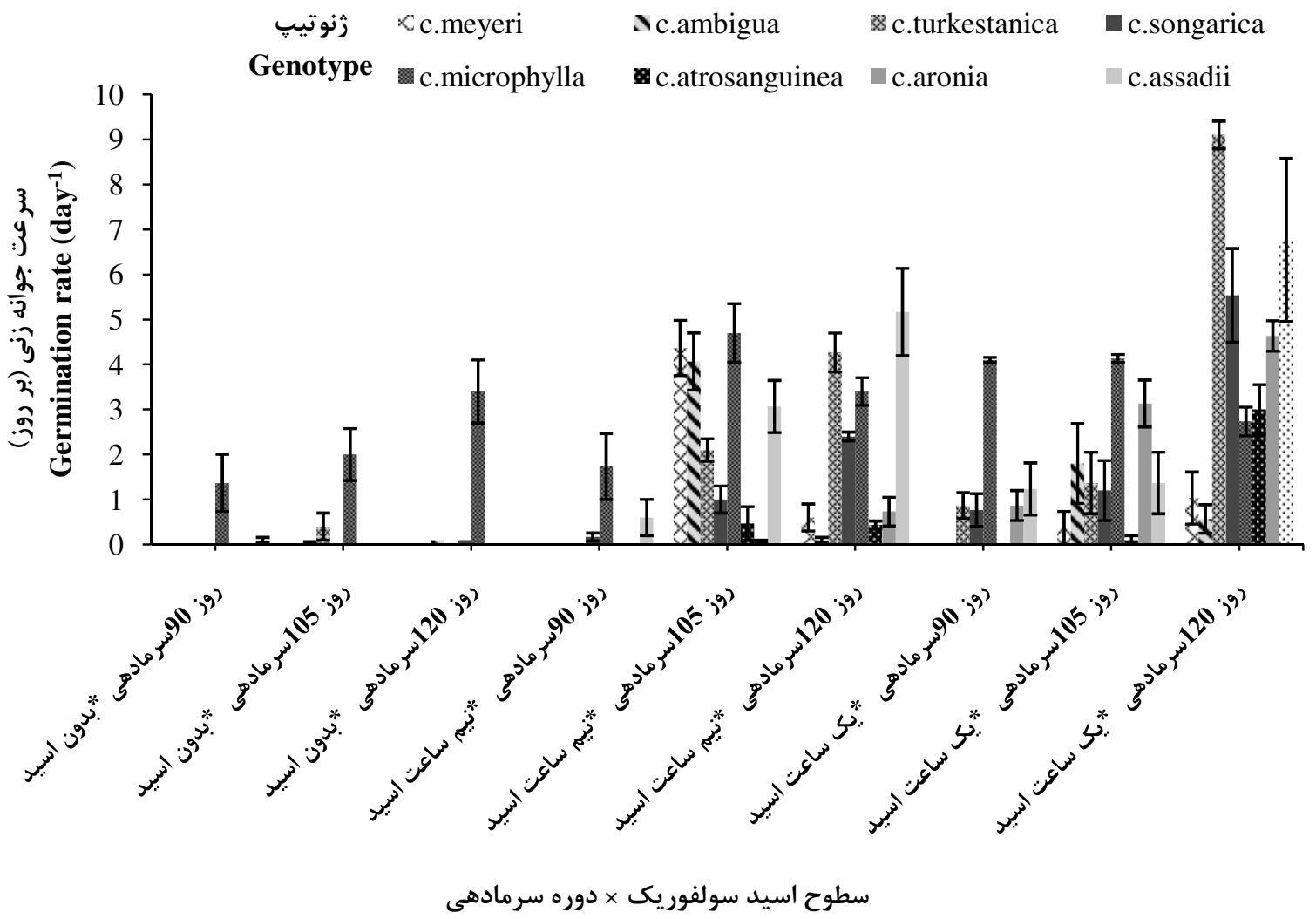

Sulfuric acid levels $\times$ chilling period

شكل r- برهمكنش تيمارهاى اسيد سولفوريك، دوره سرمادهى و رُنوتيٍ براى سرعت جوانهزنى. بارها نشاندهنده خطاى استاندارد ميانكينها

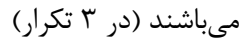

Figure 2. Effect of interactions of sulfuric acid, chilling period and genotype on germination rate. The bars represent the standard error of the means (in 3 replications).

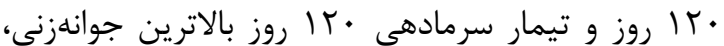
با ظهور ريشهجه كوجى با طول كم در طى دوره سرمادهى حاصل گرديد. دورههاى طولانىتر سرمادهى از

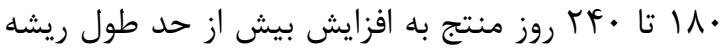
مى مردد و كشت مكانيكى را مشكل يا غيرممكن مىسازد.

\section{نتيجه}

C. بر اساس نتايج بهدست آمده زنوتيڤهاى

C. atrosanguina, C. songarica, turkestanica C. assadii , C. aronia و بالاترين درصد و سرعت جوانهزنى را در تيمار يك ساعت اسيد سولفوريك بعلاوه

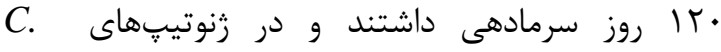
C. microphylla g C. meyeriambigua

$$
\begin{aligned}
& \text { رفع موانع فيزيولوزيكى باعث افزايش مقاومت دانه } \\
& \text { جوانهزده شده و به استقرار و رشد بعدى آن كمك مى كند }
\end{aligned}
$$

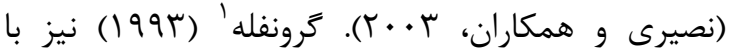

$$
\begin{aligned}
& \text { يزوهشى كه روى اثر دماى يايين بر ميزان جوانهزنى }
\end{aligned}
$$

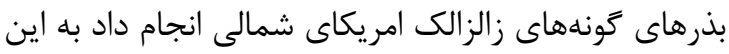

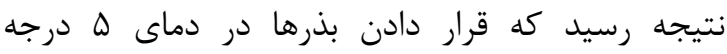

$$
\begin{aligned}
& \text { سانتى }
\end{aligned}
$$

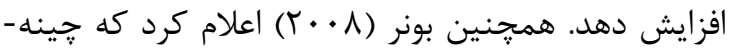

$$
\begin{aligned}
& \text { سرمايى يس از گرماى مرطوب يا دو الى سه دوره متوالى } \\
& \text { از جينه سرمايى و گرماى مرطوب براى شكستن ركود }
\end{aligned}
$$

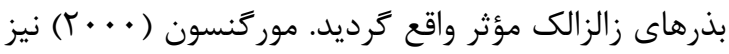

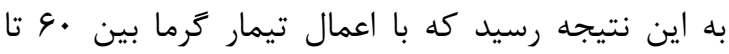

\footnotetext{
${ }^{1}$ Qrunfleh
} 


\section{همتىفر و همكاران: تسهيل جوانهزنى بذر هشت كونه زالزالك (Crataegus Spp) بومى ايران...}

$$
\text { درصد و سرعت جوانهزنى از تيمار نيم ساعت اسيد رولفوريك بعلاوه هرمادهى حاصل شد. }
$$

Agrawal, R.L. 1992. Seed technology. Oxford and IBH publishing Co. LTD. New Delhi. 376p.

Arjomandi, A. 2006. Morphological and taxonomic study of some species of Hawthorn (Crataegus) in the provinces of Golestan, Khorasan and Kerman. M.Sc. dissertation, Department of horticulture, faculty of agriculture, Shahid Bahonar university of Kerman. [In Persian with English Summary].

Bishnoi, N.R., Sheroran, I.S., and Singh, R. 1993. Effect of cadmium and nickel on mobilization of food reserves and activities of hydrolytic enzymes in germinating pigeon pea seeds. Biology Plant, 35(4): 583-589. https://doi.org/10.1007/BF02928036

Bonner, F. 2008. The woody plant seed manual. United States department of agriculture, agriculture handbook. 727p.

Brenda, B., Jenning, W., and Rawlinson, R. 2004. Crataegus saligna (willow hawthorn). University of Colorado Herbarium, Boulder, Co. 37p.

Bujarska, B. 2011. Breaking of seed dormancy, germination and seedling emergence of the common hawthorn (Crataegus monogyna Jacq.). Dendrobiology, 47: 61-70.

Christensen, K.I. 1992. Revision of Crataegus sect. Crataegus and Nothosect. Crataeguineae (Rosaceae-Maloideae) in the old world. Systematic Botany Monographs, 35: 1-199 https://doi.org/10.2307/25027810

Garber, M.P., and Morhead, D.J. 1999. Selection on production and establishment of wetland trees and shrubs. Bulletin-Cooperative Extension Service, University of Georgia, College of Agriculture (USA). 45 p.

Ghasemi, A. 2010. The final report of the project and the selection of the most suitable vegetative base for Quince, Isfahan cultivar. First edition, Isfahan Agricultural and Natural Resources Research Center. [In Persian].

Gongh, R.E. 1996. Growing trees and shrubs from seeds, Montguid Agriculture MT9604. Montana state University, 24p.

Gosling, P. 2007. Raising trees and shrubs from seed. Forestry commission practice guide. Forestry Commission. 18-28.

Heidari, M., Rahemi, M., and Daneshvar, M.H. 2008. Effects of mechanical, chemical scarification and stratification on seed germination of Prunus scoparia (Spach.) and Prunus webbii (Spach.) Vierh. AmericanEurasian Journal of Agricultural and Environmental Sciences, 3(1): 114-117.

Khoshkhoi, M. 1988. Propagation methods of ornamental plants. Shiraz University Press, 93p. [In Persian].

Makkizadeh, M., Farhoudi, R., Naghdi badi, H.A. and Mehdizadeh, A. 2006. Assigning the best treatment for increasing germination of three medicinal plants seeds: Rubia tinctourum L., Echinacea angustifolia D.C. and Myrtus communis L. Iranian Journal of Medicinal and Aromatic Plants Research, 22(2): 116-105. [In Persian with English Summary].

Mirzadeh Vaghefi, S.S., Jamzad, Z., Jalili, A., and Nasiri, M. 2013. Effect of gibberellic acid, sulfuric acid, and potassium nitrate on germination of three native Iranian hawthorn seeds. Journal of 
Forest and Wood Products. Iranian Natural Resources Journal, 66(2): 135-146. [In Persian with English Summary].

Mirzadeh Vaghefi, S.S., and Nasiri, M. 2013. The effects of physical and chemical factors on the seed germination of Crataegus assadii. Journal of Plant Research (Iranian Journal of Biology), 26(3): 366-374. [In Persian with English Summary].

Mirzadeh Vaghefi, S.S., Jamzad, Z., Jalili, A., and Nasiri, M. 2010. Study on dormancy breakage and germination in three species of hawthorn (Crataegus aminii, C. persica and C. babakhanloui). Iranian Journal of Forest and Poplar Research, 17(4): 544-559. [In Persian with English Summary].

Morgenson, G. 2000. Effects of cold stratification, warm-cold stratification and acid scarification on seed germination of 3 Crataegus species. Tree Planters' Notes 49(3): 72-74.

Nasiri, M., Arefi, H.M., and Eisvand, H.R. 2008. Seed germination in Kozal (Diplotaenia damavandica Mozaffarian, Hedge and Lamond). Seed Science and Technology, 36(1): 214-217. https://doi.org/10.15258/sst.2008.36.1.25

Peitto, B., and Di Noi, A. 2001. Seed propagation of Mediteranean trees and shrubs. APAT Press, Italy, $99 \mathrm{p}$.

Qrunfleh, M.M. 1993. Studies on the howthorn (Crataegus azarolus), A potential rootstock for Golden Delicious apple and Williams pear. Journal of Horticultural Science, 68(6):983-987. https://doi.org/10.1080/00221589.1993.11516439

Williams P.A., and Buxton R.P. 1986. Howthorn (Crataegus monogyna) population in midCanterbury. New Zealand Ecological Society, 9: 11-17. 


\title{
Facilitating Seed Germination of Eight Species of Hawthorn (Crataegus spp.) Native of Iran, Using Chemical Scarification and Cold Stratification
}

\author{
Masume Hematifar ${ }^{1}$, Ali Tehranifar ${ }^{2, *}$, Bahram Abedi ${ }^{3}$, Hasan Akbari Bishe ${ }^{4}$ \\ ${ }^{I}$ M.Sc. Student of Horticulture and Landscape, Ferdowsi University of Mashhad, Mashhad, Iran \\ ${ }^{2}$ Professor, Department of Horticultural Science and Landscape, Ferdowsi University of Mashhad, \\ Mashhad, Iran \\ ${ }^{3}$ Assistant Professor, Department of Horticultural Science and Landscape, Ferdowsi University of \\ Mashhad, Mashhad, Iran \\ ${ }^{4}$ Academic Member in the Center for Agricultural Research in Isfahan, Isfahan, Iran \\ *Corresponding author, E-mail address: tehranifar@um.ac.ir
}

(Received: 08.02.2017 ; Accepted: 17.03.2018)

\begin{abstract}
Given the medicinal and ornamental properties of Hawthorn (Crataegus spp.), and given that there are some problems in its propagation, which is due to the hard cover of the seeds and immature embryo, working out techniques that can facilitate the process of seeds' germination is of great import. Thus, the present study sought to identify the best method for the purpose of breaking the seed dormancy of 8 species of native hawthorn of Iran. The study was carried out as factorial with a completely randomized design and had three replications. The first, second and third factors were, respectively species of Hawthorn in eight levels, sulfuric acid in three levels (half and an hour versus non-treated (control) and chilling treatment in three levels (90, 105 and 120 days, respectively). The results showed that the highest percentage of germination $(32 \%)$ and germination rate $\left(9.1\right.$ day $\left.^{-1}\right)$ were obtained under the interaction of sulfuric acid treatment for one hour, followed by a 120-day chilling period in C.turkestanica, which had a significant difference with other treatments. It is concluded that hawthorn seeds have deep endocarp and physiological dormancy. The interaction of Sulfuric acid treatment and moist chilling play an important role in increasing the percentage and speed of germination of Hawthorn seeds.
\end{abstract}

Keywords: Sulfuric acid, Seed dormancy, Germination percentage, Cold stratification

\section{Highlights:}

1. Achieving the best way to break the dormancy of Hawthorn seeds in different species and genotypes.

2. Shortening the seeds' germination time.

DOI: $10.29252 / y u j s .4 .2 .13$ 